\title{
Aportes Teóricos da Ação Comunicativa de Habermas para as Metodologias Ativas de Aprendizagem
}

\author{
Theoretical Contributions of Habermas' \\ Communicative Action for the Active \\ Learning Methodologies
}

Cássia Regina Rodrigues Nunes ${ }^{1}$ Amauri Porto Nunes ${ }^{2}$

PALAVRAS-CHAVE

-Ética;

-Bioética;

- Educação em Saúde.

KEY-WORDS

- Ethics;

- Bioethics;

-Education in Health.

Recebido em: $15 / 09 / 2004$

Reencaminhado em: 02/07/2005

Aprovado em: 22/08/2005

\section{RESUMO}

Neste artigo buscamos nos fundamentar na teoria da ação comunicativa de Habermas para sua aplicaça na aprendizagem realizada em pequenos grupos, nas metodologias ativas (PBL e Problema. tização). Utilizamos pequenos grupos de estudantes como uma estratégia de aprendizagem nas metodologias ativas e, neste trabalho queremos mostrar como a Teoria da Açăo Comunicativa, de Habermas, pode ser utilizada nos mesmos para o deservolvimento de melhor interafäo atraves da intersub. jetividade, pois através desta cria-se a possibilidade do reconhecimento do álter e de si, e, a partir desse ponto, a construça do consenso. Habermas é o grande pensador da escola de Frankfurt, e sua obra segue a mesma linha de seus predecessores, Horkheimer e Adorno, tentando, porém, uma reconstrução e amplią̧ão da teoria crítica da sociedade. O autor propóe uma concepçăo da sociedade que a considere simultaneamente como sistema e como 'mundo da vida'. Acredita ainda, que a ação comunicativa é constituinte da sociedade e, através desse pressuposto, tenta reconstruir a filosofia da racionalidade, portanto com grandes implicaçoes éticas, pois, para ele, através do desenvolvimento cognitivo torna-se possível uma compreensão do mundo descentrada do sujeito, não egocêntrica. $A$ Teoria da Ação Comunicativa abrange todos os ámbitos da racionalidade e da ação: ético, social, psicológico, enfim, de tudo que se relaciona ao homem e suas interaçoes, podendo ser utilizado em pequenos grupos de estudantes como modelo de desenvolvimento moral e ético.

\begin{abstract}
In this article we aim to apply Habermas' theory of communicative action in active methodologies (Problem-Based Learning) to the learning/teaching process in small groups. We show how the theory of communicative action can be used for developing a better interaction inside the group, through intersubjective recognition providing the possibility of recognizing the alter" and themselves and, from this point on, being able to achieve a consensus. Habermas, today's great thinker of the Frankfurt School, follows in his work the line of his predecessors, Horkheimer and Adorno, but trying to rebuild and amplify the critical theory of society. The author proposes a concept of society considering it at the same time a system and a "lifeworld: He also believes communicative action to be $a$ constituent of society and, based on this idea, attempts to rebuild the philosophy of rationality. Habermas' communicative action theory has great ethical implications. According to him, cognitive development allows a global, "decentered" not egocentric understanding of the world. The communicative action theory involves all fields of rationality and action, ethical, social and psychological, in summary, everything related to man and his interactions, thus being a valuable model to be used for moral and ethical development in small groups of students.
\end{abstract}


Qunuto um din a fortalezn da razảo centradn no sujeito for demolidn, tambím desabaró o logos, que sustentou por muito tempo a interiorizaçno protegida pelo poder, oca por dentro $\mathrm{C}$ agressiva por forn. O logos terí, entio, de render-se no seu outro, seja este qual for. jCrGen Hageriuas

\section{INTRODUÇĀO}

A educaçāo hoje exige postura aberta a mudanças e revisão de paradigmas. $O$ conhecimento atual ć amplo e complexo, tornando-se necessária a interdisciplinaridade. Torna-se imprescindivel uma busca e critica constantes das informaçōes para que a atuaçāo profissional possa ser consciente $e$ baseada em evidências cientificas. Talvez o ponto fundamental de toda essa mudança seja a necessidade de olhar o ser humano em sua totalidade e agir com eticidade, buscando justamente integrar o conhecimento que ao longo do tempo, principalmente do século XX, ficou fragmentado. Para atingir essas metas, inovaçōes sāo propostas nos modelos de ensino dos cursos de formaçāo profissional na área de saúde.

Nessas práticas pedagógicas inovadoras, o aprendizado é centrado no aluno, que num processo dialógico de construçāo coletiva e progressiva do conhecimento, desenvolve atividades em pequenos grupos, acompanhados pelo professor. Esse, nesse caso, desempenha o papel de facilitador na construçāo do conhecimento, ou seja, acompanha o trabalho do grupo, muito mais preocupado com o processo metacognitivo.

Espera-se que com as metodologias ativas, utilizadas nos cursos de saúde, preparar profissionais mais ativos, criticos e transformadores da realidade; com a capacidade de trabalhar em equipe, de relacionar-se melhor com o paciente, compreendendo a sua situaçāo de vida (processo viver-adoecer-morrer), intervindo nesta, de modo ético e consciente. Estes pressupostos estāo presentes nas metodologias de aprendizagem, implantadas na Faculdade de Medicina de Marília: o ABP (A prendizagem Baseada em Problemas) e a Problematizaçāo, que tem no trabalho em grupo a principal estratégia para atingir essas metas.

Observamos em nossa prática que o trabalho em grupo bem orientado proporciona a oportunidade de o aluno obter um desenvolvimento no seu agir, através da auto-reflexāo e do confronto de idéias. Nesse processo o estudante é estimulado a lançar-se à discussāo com maior autonomia, organizando suas idéias em relaçāo ao conteúdo abordado, constantemente avaliando o seu próprio desempenho, do grupo e do professor (facilitador ou tutor). No momento em que expōe seu pensamento, encontra idéias contrastantes que podem possibilitar, quando há preparo do tutor, um movimento dia- lético e continuo de reavaliação de idéias e posiçōes adotadas anteriormente. Existe, assim, a possibilidade de ampliar suas perspectivas para além da auto-reflexão, levando à compreensāo da pluralidade de idéias e valores existentes.

Através da intersubjetividade, cria-se a possibilidade do reconhecimento do álter e de $\mathrm{si}, \mathrm{e}$, a partir desse ponto, a construçāo do consenso. Buscamos, assim, fundamentação na teoria da açāo comunicativa de Habermas para o desenvolvimento de um procedimento que torne possivel encontro e proximidade entre os sujeitos.

\section{METODOLOGIAS ATIVAS DE APRENDIZAGEM}

Na sociedade moderna, complexa e, em constante mudança, o ensino tradicional, que centra o aprendizado na transmissāo do conhecimento pelo professor, perde progressivamente seu suporte, pois o conhecimento é hoje amplo demais, e o acúmulo de informaçōes de nada vale se estiver isolado da capacidade de resolver novos problemas que surgem diariamente. Nessa nova realidade, a capacidade criativo-pragmática torna-se mais importante que a simples ilustração. Em decorrência dessa constataçāo, busca-se cada vez mais colocar em prática metodologias de ensino-aprendizagem com possibilidade de desenvolver nos alunos tais competências.

Um recente relatório da UNESCO' coloca essa problemática, deixando bem clara a premència em desenvolver o processo educacional nāo apenas voltado para aquisiçāo de conhecimentos técnicos específicos, mas sustentado em quatro pilares básicos: aprender a conhecer, aprender a fazer, aprender a conviver e aprender a ser.

Segundo esse mesmo relatório, já nāo é mais possivel e nem adequado apenas transmitir grandes quantidades de in. formaçōes sem dar subsidios para que o estudante consiga emergir nas ondas de um mar de informaçōes e aproveitar cada momento de aprendizagem que lhe for oportunizado. Dessa forma, ele será capaz de atualizar-se, aprofundar-se no conhecimento e enfrentar situaçōes novas colocadas pela prática, hoje e no futuro!

Dentro desse enfoque, parece-nos que as metodologias ativas de aprendizagem têm maior adequação ao perfil de profissional que se almeja, uma vez que incentivam a busca ativa de informaçōes, o trabalho em equipe, proporcionam a análise crítica das fontes consultadas, desenvolvem a habilidade de avaliaçāo do seu desempenho individual e do grupo e proporcionam o reconhecimento da importância da interrelaçāo com o outro na construçào do conhecimento. As me• todologias ABP e Problematizaçāo guardam estreita relaçāo com os pressupostos filosófico-pedagógicos de John Dewey e 
Paulo Freire, respectivamente, pois, visam ao desenvolvimento de cidadãos conscientes das realidades vividas e participantes de mudanças baseadas num senso crítico.

John Dewey e Paulo Freire acreditavam que o processo ensino-aprendizagem se inicia quando os estudantes se defrontam com conflitos, os quais despertam seus interesses, e os problematizam. No caso do ABP os alunos, inicialmente, analisam uma situação-problema e idertificam nessa situação os conflitos que serāo, em um primeito momento, discutidos pelo grupo com base em seus conhecimentos prévios (conhecimento leúrico e/ ou vivencias). Num segundo momento os alunos identificarāo os pontos falhos no seu conhecimento e então partirāo para a busca ativa de conhecimento para fundamentaçāo teórica que resolva as lacunas percebidas anteriormente.

Em uma sessão de tutoria subseqüente, os alunos retornam com os dados obtidos e fazem nova discussāo até que se satisfaçam as necessidades imediatas para entendimento e/ ou resolução dos conflitos e lacunas identificadas. Esse processo pode se repetir quantas vezes forem necessárias em uma mesma situação-problema. Após ser alcançado o consenso nessa discussão, o grupo tenta realizar generalizaçōes e imaginar variaçũes sobre o mesmo tema para sedimentar e reaplicar o conhecimento adquirido. $O$ ponto fundamental é a metacognição, isto é, o aprendizado do processo de análise dos problemas, raciocínio, construçāo de novo conlecimento e aplicação do mesmo, e não apenas o conteúdo material de conhecimento adquirido. O conhecimentoé construido pelos próprios alunos nesse processo dialógico, de maneira progressiva, em abordagem interdisciplinar, além de haver também a possibilidade do desenvolvimento de habilidades de trabatho em equipe e de relacionamento interpessoal.

Paulo Freire, ao qual nos reportamos na metodologia da problematização, propōe alguns passos para o aprendizado. A partir da vivència real dos educandos, são identificados pelo educador os temas geradores (assuntos de grande interesse dos educandos em seu cotidiano) que, nesse primeiro momento, se encontram ainda nāo problematizados. Esses temas geradores são apresentados para os educandos que reaiizam um trabalho de problematizaçāo desses temas geradores, isto é, realizam uma contextualização desses temas em suas vivências. A partir dessa problematizaçāo, busca-se fundamentaçāo teórica na tentativa de entender os problemas levantados. Os alunos realizam, entāo, uma reflexāo crítica, num processo dialógico entre educadoreseducandos, realizado também en pequenos grupos, tentando identificar quais as causas históricosociais desse problema, e a partir dessa tomada de consciència propōem uma açāo social para alcançar uma mudança da realidade.
Freire pretende que o educando faça uma correlação dos problemas com o poder, com a perversidade das instituiçōes, com a demagogia das elites, enfim, prepara o educando para viver como cidadão, vivenciando o problema, entendendo-o e procurando soluçūes articuladas para os mesmos².

Nas duas metodologias, o professor desempenha a função de facilitador do processo e não de transmissor de conteúdos teóricos descontextualizados, buscando a formaçāo autônoma, critica e transformadora da realidade.

Venturelli, baseadonn pensamento de Freire, ressalta que as metodologias ativas estão calcadas numa prática centrada no aluno. Estes não são mais ouvintes e sim, co-investigadores críticos num diálogo com o professor ${ }^{3}$.

Para que o professor possa acompanhar a busca e discussão realizadas, assim como a capacidade de os alunos interagirem, ressaltamos que um dos pilares fundamentais da $A B P$ e da Problematizaçāo é o trabalho em pequenos grupos, que promove a discussāo, a compreensāo (não somente o uso da memória, mas de raciocínio) e o trabalhoem equipe. A educação, segundo Venturelli, continua extra-muro universitário, e o estudante tem de estar preparado para atuar nos problemas e situaçōes de vida, através do desenvolvimento da capacidade de 'aprender a aprender'. Essa afirmaçāo vem ao encontro dos princípios pedagógicos propostos por Detvey e Freire, em que os resultados são satisfatórios quando o estudante é capaz de encontrar soluçōes para novos problemas através das capacidades de auto-aprendizado e da pedagogia autônoma desenvolvidas pelos métodos utilizados.

\section{TEORIA DA AÇĀO COMUNICATIVA}

Habermas é um grande pensador da escola de Frankfurt, e sua obra segue a mesma linha de seus predecessores (Horkheimer e Adorno), tentando, porém, uma reconstrução e ampliaçāo da teoria crítica da sociedade. Nos seus estudos sobre a comunicação, interessado pela filosofia analítica da linguagem, da ciência e na psicologia do desenvolvimento mental, percorre a história da teoria social fazendo uma análise das patologias sociais, consideradas por ele intrínsecas ao capitalismo avançado. Está de acordo com seus predecessores, quando diz que na sociedade moderna há um crescimento exageraclu dos aspectos instrumentais, culminando com a objetificaçāo e mediatizaçāo dos indivíduos. No entanto, acredita que a crítica apenas negativa nāo é frutifera e tenta, em sua reconstrução, buscar alternativas para estes problemas.

Habermas acredita que a espécie humana evoluiu, organizando-se historicamente em diversos tipos de sistemas sociais, sendo que cada um desses sistemas pressupōe uma in- 
ter-relação própria dos subsistemas (sociocultural, econômico e político). Através da histúria, a humanidade foi-se desenvolvendo e aumentando a complexidade dessas interaçōes no sentido de criar sistemas de auto-preservaçāo'. Para que seja possivel essa interaçāo entre os diversos indivíduos $e$, por conseguinte, entre os diversos subsistemas, faz-senecessária a existência de u m mundo simbólico compartilhado pelos seus integrantes. Habermas acredita que o tecido de fundo que faz a mediaçāo dessa inter-relaçāo entre os subsistemas é a linguagem, entendida como ferramenta pragmática que serve nāo apenas para transmissāo de informaçōes técnicas, mas também para compartilhamento de representaçōes simbólicas acerca do mundo, introjetando papéis e normas de açāo.

Partindo desse pondo de vista pragmático, Habermas acredita que o ser humano articula suas açōes sempre em função de suas necessidades e interesses e, para alcançar esta finalidade, utiliza-se da linguagem como meio de expressāo e, principalmente, como ferramenta para, direta ou indiretamente, alcançar a satisfaçāo desses interesses.

Nas sociedades modernas, o predominio da racionalidade instrumental tem provocado uma ruptura entre o àmbito do matcrial c dos valores, entre pensamento c aşão, teoria c práxis, com a hipertrofia do positivismo. Habermas se opỏe a este, propondo um resgate da reflexão filosófica sobre o sentido e os fins da vida, na tentativa de equilibrar novamente essa relaçāo.

Acredita ainda que a ação comunicativa éconstituinte da sociedade e, através desse pressuposto, tenta reconstruir a filosofia da racionalidade. Ele diferencia o agir e o falar, em que açōes em sentido estrito, ou atividades nāo lingüisticas, sāo orientadas para um fim; os atos intervêm no mundo para realizar fins propostos, utilizando meios adequados. Por outro lado, as açōes lingüísticas sāo atos onde um falante tenciona chegar a um entendimento com outro falante sobre algo no mundo.

Habermas tenta recuperar a reflexāo e a discussāo racional sobre as formas e o fim da vida, nos quais, o sentido e a racionalidade se dào pela discursividade; no processo dialógico é que se constitui a personalidade dos indivíduos nos grupos suciais.

Ele considera o trabalho e a linguagem características e originárias da vida e evolução humanas. Para ele, o que evolui nāo é o macro-sujeito histórico, mas as sociedades e os sujeitos que nela atuam, assim como as regulamentaçōes que orientam as açōes humanas. Acredita que os interesses que motivam toda ação humana, os diferentes tipos de ação e o conhecimento próprio de cada uma, sāo elementos básicas dentro desta evoluçāo. Sendo assim, uma teoria crítica da so- ciedade só pode ser reconstruída com base numa concepção sistêmica e articulada de interesses, açōes e conhecimentos. ${ }^{4}$

Para Habermas, há tipos de ação que são dependentes dos tipos de interesse: técnico, prático e emancipativo. Nesse sentido, $o$ autor coloca três tipos de ação: a açāo estratégica, a açāo orientada por normas e a açāo dirigida ao entendimento.

A 'ação estratégica' é aquela que se desenvolve a partir de interesses comuns para atingir uma finalidade, em uma lógica utilitarista, sendo, portanto, instrumental-teleológica. A 'açāo orientada por normas' relaciona-se com o interesse prático e coordena as interações pessoais que ocorrem no cotidiano. Esse tipo de ação pressupõe a existência de papéis sociais e normas, introjetados pelos indivíduns e reconhecidos pelo grupo, segundo os esquemas sistêmicos do mundo social no qual vivem e, tem por finalidade a superaçāo dos conflitos sociais. Por sua vez, a nçño comunicntion é correlata ao interesse crítico-emancipatório que busca o entendimento através da argumentaçāo. Assim, chegamos ao conceito de açāo comunicativa, que é um tipo especifico de açāo voltada ao entendimento. Habermas coloca requisitos fundamentais para sua ocorrência, a saber: a finalidade da açāo deve ser autenticamente expressa no ato de fala, sem subterfúgios; as pretensões de validez dos interlocutores devem poder ser criticadas; o falante e o ouvinte devem ocupar lugares próprios no processo dia lógico, de tal maneira que tenham participaçāo em um plano de igualdade; e finalmente, a açāo comunicativa deve sempre ter a possibilidade implícita de levar a um entendimento racional, baseado na conviç̧ão e nunca na coaçāo. ${ }^{4}$

Habermas propõe uma concepçāo da sociedade que a considere simultaneamente como sistema e como 'mundo da vida'. O autor denomina 'mundo da vida' o lugar transcendental onde aquele que fala e aquele que ouve se encontram com padrōes de interpretaçōes desenvolvidos socioculturalmente e individualmente, buscando o entendimento. ${ }^{5}$

A produçāo da cultura da sociedade e a manifestaçāo de personalidade se dāo nas interaçōes ocorridas no cotidiano, mediadas pela comunicaçāo. Para Habermas, a comunicaçāo faz a mediaçāo no processo de aprendizado social, necessário para a sobrevivência. O ponto de partida é a compreensāo baseada na experiéncia pessoal, que adquire coerência eidentidade quando é reconhecida intersubjetivamente, vinculando o indivíduo à comunidade. A política e a economia sāo determinantes da vida social, assim como a dominaçāo politica e econômica influenciam ideologicamente a formaçāo da cultura e da tradição. Daí deriva a necessidade da teoria crítica como forma emancipatória dos padrōes de pensamento que limitam a autocompreensāo. Esse interesse emancipatório é crescente na sociedade moderna de classes, devido ao inte- 
resse pela sobrevivência ${ }^{6}$. Habermas coloca que, num certo sentido, todo conhecimento se relaciona com o interesse emancipatório, que está ligado à noção cultural de autopreservação e com o interesse emergente em atingir a 'vida boa'.6

Habermas fala da dificuldade em estabelecer regras na modernidade, constata a hostilidade metodológica contra a razão, a pouca investigação nesse campo e a crítica da razão decorrente de um contra discurso de quase 200 anos. Porém, vários autores da modernidade se dedicam a esclarecer o discurso da nova crítica da razão. Desse processo deriva o conceito de razão situada, entendendo que a razão faz a mediação concreta dos homens na práxis social.

Habermas sustenta que essa práxis se efetiva numa dimensão histórica e mediatiza a natureza subjetiva dos indivíduos em suas necessidades, com uma natureza objetivada no trabalho ? . Não haveria a necessidade da compreensão, da razão crítica descentrada do sujeito, se não fosse a vida em comunidade e, do mesmo modo, não seria possível a razão compreensiva sem o outro. Nesse sentido, Habermas respalda-se em Freud e Nietzshe,"a razão não existe sem o seu ou-
tro - do ponto de vista funcional tro - do ponto de vista funcional - torna-se necessária mediante esse outro".7 Porém, o autor supera seus antecessores quando formula o pensamento de descentramento do sujeito e constata a necessidade de situar-se no "paradigma da intersubjetividade", em que o 'eu' se constrói num processo de aprendizagem constitutivamente intersubjetivo. ${ }^{4}$

O pensamento de Habermas se desencadeia num sentido extremamente ético, no que diz respeito a uma racionalidade em prol de discutir o sentido existencial, emancipatório e não somente instrumental e técnico das formas de vida. É, portanto, inevitável conduzir seus ensinamentos para o ensino em geral e da ética especificamente, uma vez que a reflexão de Habermas contribui excepcionalmente para o entendimento da vida humana individual e coletiva.

\section{CONCLUSÃO}

Consoante as mudanças exigidas em nosso tempo frente à pluralidade de valores e costumes, informações cada vez mais amplas e acessíveis, a Teoria da Ação Comunicativa e, conseqüentemente, a ética do discurso é, para nós, um referencial extremamente indispensável. Não é, no entanto, de fácil compreensão e abstração, principalmente para nós profissionais da área da saúde, mas torna-se fundamental no ensino da ética, como também acreditamos que seja a sua apli-
cação de grande alcance.

A Teoria da Ação Comunicativa abrange todos os âmbitos da racionalidade, da ação, do ético, social e psicológico, enfim de tudo que se relaciona com o homem e suas interaçōes.
Ela faz um elo com todos esses aspectos da vida e do conhecimento e, portanto, deve ser usada nas metodologias ativas de aprendizagem, como uma explicação filosófica que dá coerência aos pressupostos dos projetos pedagógicos já mencionados. Para nós, o conhecimento e a aplicação dessa teoria seriam o pano de fundo do ensino integrador, participativo e ético, isto é, na capacidade de projetar no futuro as escolhas de hoje, no modo de ser e fazer consciente.

A sua aplicação possibilita ação racional mais solidária, mais justa, e, acima de tudo, desenvolvida, buscando a emancipação humana. Objetivando portanto, uma sociedade que
valorize a vida.

A sociedade atual possui características próprias que a diferencia cada vez mais das anteriores: sua crescente complexidade, desenvolvimento acelerado da tecnociência e a discutida ausência de referenciais morais universais. Faz-se necessário, enfim, a busca de alternativas educacionais que permitam o desenvolvimento da capacidade do individuo de enfrentamento e resolução dos problemas advindos dessa si-
tuação.

A evolução da sociedade e da ciência devem ser integradas, isto é, não é efetiva a evolução do conhecimento desvinculada da evolução do espírito, correndo-se o risco de chegar-se à negação dos próprios objetivos que deram origem ao processo de esclarecimento, emancipação humana como espécie, em relação à natureza, e como indivíduo em relação à opressão da própria sociedade. Concluímos, portanto, nessa perspectiva, que se faz necessário buscar na educação referenciais que se coadunem com paradigmas inovadores e integradores e que tenham como característica a possibilidade de proporcionar um desenvolvimento moral do indivíduo, ao mesmo tempo, que não seja autoritário ou dogmático.

Assim, após a aproximação com a proposta da Teoria da Ação Comunicativa de Habermas, que nos possibilita um diagnóstico da sociedade atual, percebemos também, claramente, que a mesma proporciona uma nova abordagem, tanto do agir ético no estabelecimento de princípios morais que possam servir de referência para o agir humano quanto de referencial para a educação, pois se adapta perfeitamente às propostas de ensino-aprendizagem ativas, desenvolvidas em pe-
quenos grupos.

A busca de formação dentro de perfis profissionais desenhados com o intuito de ter no mercado de trabalho profissionais com iniciativa, criativos, que saibam resolver problemas, deve buscar, além disso, formar 'indivíduos' mais humanos, críticos, que consigam ampliar sua visão de mundo, entendendo a conformação da sociedade e que possam atuar de modo a transformá-la numa sociedade melhor. A ação dis- 
cursiva oferece uma perspectiva de reconhecimento de valores plurais e, reconhecendo os requisitos fundamentais para a sua ocorrência, possibilita ação mais solidária, mais justa.

O trabalho de desconstrução, por mais furioso que seja, possui consequiências identificáveis somente quando o paradigma da consciência de si, da auto-relação de um sujeito que conhece e age solitário é substituído por outro - pelo do entendimento recíproco, isto é, da relação intersubjetiva entre individuos que, socializados por meio da comunicação, se reconhecem reciprocamente $^{7}$

\section{REFERÊNCIAS}

1. Unesco. Education for all 2000: Global assessment synthesis. Dakar; 2000.

2. Ghiraldelli Junior P. Didática e teorias educacionais. Rio de Janeiro: DP\&A; 2000.
3. Venturelli J. Educación medica: Nuevos enfoques, metas y métodos. Washington: OPS-OMS; 1997.

4. Boladeras M. Comunicación, ética y política: Habermas y sus críticos. Madri: Tecnos; 1996.

5. Habermas J. Teoría de la acción comunicativa, II: Crítica de la razón funcionalista. Madri : Taurus; 1992.

6. Ingram D. Habermas e a dialética da razão. 2.ed. Brasília: UnB; 1997.

7. Habermas J. O discurso filosófico da modernidade. São Paulo : Martins Fontes; 2000.

\section{Endereço para correspondência:}

Av. Sampaio Vidal, 35-A

Centro - Marília-SP

CEP: $17501-441$ 